\title{
A sword threatening the heart: The scimitar syndrome
}

\author{
Vladimiro L. Vida, MD, $\mathrm{PhD},{ }^{\mathrm{a}}$ and Alvise Guariento, $\mathrm{MD}^{\mathrm{b}}$
}

Video clip is available online.

Scimitar syndrome (SS) is a rare congenital heart anomaly consisting of anomalous venous drainage of part or the entire right lung into the upper portion of the inferior vena cava (IVC), right lung hypoplasia, and a variable systemic arterial blood supply to the right lung. ${ }^{1,2}$

This malformation has been described by many pathologists over time. In an article published in 1956 by Halasz and colleagues, ${ }^{3}$ the word scimitar was used for the first time to describe the shape of this anomalous pulmonary venous connection. However, it was only in 1960 that Catherine Neill and colleagues ${ }^{4}$ named the syndrome, characterizing it and linking it to the radiologic appearance of a sword adjacent to the edge of the right heart that can sometimes be found at diagnosis.

The incidence of SS is relatively low, representing $3 \%$ to $6 \%$ of the partial anomalous venous connections. ${ }^{1}$ Previous studies were based on single-center experiences or rather small, multicenter studies. ${ }^{5-13}$ However, our group was recently able to conduct a multicenter study on behalf of the European Pediatric Cardiology Association and the European Congenital Heart Surgeons Association. ${ }^{14}$ This led to the collection of nearly 500 patients with SS from 51 centers, the largest series of patients with SS evaluated so far. In this review, we arbitrarily divided patients into 3 groups according to their age at diagnosis: neonates/infants $(<1$ year), children (between 1 and 10 years), and adolescents/adults (Table 1).

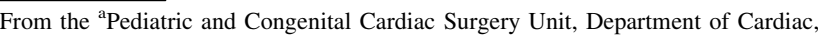
Thoracic, Vascular Sciences and Public Health, University of Padua, Padua, Italy; and ${ }^{b}$ Department of Cardiac Surgery, Boston Children's Hospital, Boston, Mass.

Read at the 99th Annual Meeting of The American Association for Thoracic Surgery, Toronto, Ontario, Canada, May 4-May 7, 2019.

Received for publication Nov 21, 2019; revisions received Nov 21, 2019; accepted for publication Jan 3, 2020; available ahead of print Feb 17, 2020.

Address for reprints: Vladimiro L. Vida, MD, PhD, Pediatric and Congenital Cardiac Surgery Unit, Department of Cardiac, Thoracic, Vascular, Sciences and Public Health, University of Padua, Via Giustiniani 2, 35100 Padua, Italy (E-mail: vladimiro.vida@unipd.it).

JTCVS Techniques 2020;1:75-80

2666-2507

Copyright (C) 2020 The Authors. Published by Elsevier Inc. on behalf of The American Association for Thoracic Surgery. This is an open access article under the CC BY-NCND license (http://creativecommons.org/licenses/by-nc-nd/4.0/).

https://doi.org/10.1016/j.xjtc.2020.01.017
}

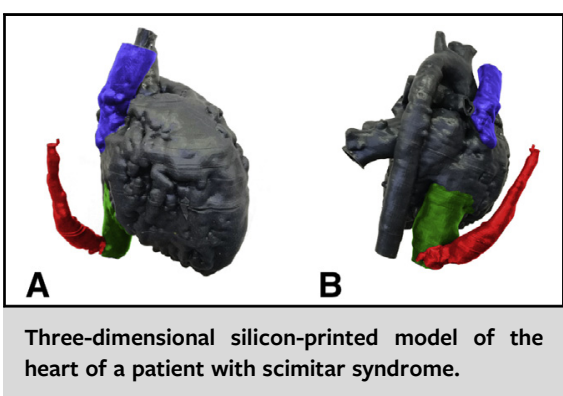

$$
\begin{aligned}
& \text { CENTRAL MESSAGE } \\
& \text { This review deals with the natural } \\
& \text { and surgical history of patients } \\
& \text { with scimitar syndrome, } \\
& \text { describing the clinical presenta- } \\
& \text { tion and possible results based } \\
& \text { on the choice of treatment. }
\end{aligned}
$$

See Commentary on page $\mathbf{8 1 .}$

\section{ANATOMICAL AND PHYSIOLOGICAL SPECTRUM}

The embryological origin of the syndrome is still unknown and may be related to a right/left disturbed signaling. ${ }^{15}$ The typical scimitar vein (SV) usually provides drainage for the entire lung in $60 \%$ of cases. This vein may be stenotic in $20 \%$ of patients with a supra or infradiaphragmatic course, representing an important factor of poor prognosis. ${ }^{15}$ Right lung hypoplasia (70\% of cases) of varying degrees can be identified and is typically associated with dextrocardia $(50 \%$ of cases) and systemic arterial supply (50\% of cases) (Table 1). Atrial septal defect is present in $50 \%$ of the patients, but other complex congenital heart diseases (CHDs) may occur in up to $20 \%$ of patients. The remaining patients have isolated SS forms (approximately $40 \%$ of cases). ${ }^{14}$

The anomalous venous return inevitably leads to a left-toright shunt, with an increase in the pulmonary-systemic flow (Qp/Qs) ratio and consequent right ventricular overload and dilation. Pulmonary arterial hypertension may occur in $30 \%$ of cases and is observed mainly in neonates/infants, in patients with $\mathrm{CHD}$, and more rarely in isolated SS forms. This factor is widely recognized as one of the main determinants of poor prognosis. $8,9,14$

The diagnosis generally includes an echocardiographic evaluation in almost all patients, catheterization in more 
TABLE 1. Overall demographic, clinical, and instrumental data and outcomes according to the age of patients at diagnosis of a series of patients with a diagnosis of scimitar syndrome $(n=485)$

\begin{tabular}{|c|c|c|c|c|c|}
\hline & \multirow[b]{2}{*}{ Overall } & \multicolumn{3}{|c|}{ Age groups (at diagnosis) } & \multirow[b]{2}{*}{$P$ value } \\
\hline & & Neonate/infants (0-1 y) & Children $(\geq 1-10$ y) & Adolescents/adults $(\geq 10$ y) & \\
\hline Number of patients* & $485(100 \%)$ & $\mathrm{n}=282(58 \%)$ & $\mathrm{n}=113(23 \%)$ & $\mathrm{n}=90(19 \%)$ & \\
\hline Sex, male* & $180(37 \%)$ & $116(41 \%)$ & $43(38 \%)$ & $21(23 \%)$ & .03 \\
\hline $\begin{array}{l}\text { Heart position } \\
\text { Dextrocardia* } \\
\text { Mesocardia* } \\
\text { Levocardia* }\end{array}$ & $\begin{array}{r}240(49 \%) \\
83(17 \%) \\
163(33 \%)\end{array}$ & $\begin{array}{r}148(52 \%) \\
48(17 \%) \\
86(30 \%)\end{array}$ & $\begin{array}{l}61(54 \%) \\
19(17 \%) \\
33(29 \%)\end{array}$ & $\begin{array}{l}31(34 \%) \\
16(18 \%) \\
43(48 \%)\end{array}$ & .05 \\
\hline Isolated forms* & $186(38 \%)$ & $81(29 \%)$ & $57(50 \%)$ & $48(53 \%)$ & .003 \\
\hline $\begin{array}{l}\text { Associated CHD* } \\
\text { Simple CHD* } \\
\text { Complex CHD* } \\
\text { Atrial septal defect* }\end{array}$ & $\begin{array}{l}299(62 \%) \\
198(41 \%) \\
101(21 \%) \\
243(50 \%)\end{array}$ & $\begin{array}{r}199(71 \%) \\
116(41 \%) \\
83(29 \%) \\
156(55 \%)\end{array}$ & $\begin{array}{l}60(53 \%) \\
49(43 \%) \\
11(9.7 \%) \\
56(46 \%)\end{array}$ & $\begin{array}{c}40(44 \%) \\
33(37 \%) \\
7(7.8 \%) \\
35(39 \%)\end{array}$ & .003 \\
\hline Right pulmonary hypoplasia* & $346(71 \%)$ & $220(78 \%)$ & $76(67 \%)$ & $50(55 \%)$ & .003 \\
\hline $\begin{array}{l}\text { Degree of right pulmonary } \\
\text { hypoplasia } \\
\text { Mild* } \\
\text { Moderate* } \\
\text { Severe* }\end{array}$ & $\begin{array}{r}204(59 \%) \\
96(28 \%) \\
46(13 \%)\end{array}$ & $\begin{array}{r}115(52 \%) \\
65(30 \%) \\
40(18 \%)\end{array}$ & $\begin{array}{c}50(66 \%) \\
21(28 \%) \\
5(6 \%)\end{array}$ & $\begin{array}{c}39(78 \%) \\
10(20 \%) \\
1(2 \%)\end{array}$ & .003 \\
\hline Symptoms at diagnosis* & $353(73 \%)$ & $220(78 \%)$ & $73(65 \%)$ & $60(67 \%)$ & .047 \\
\hline Cardiac symptoms* & $227(47 \%)$ & $168(60 \%)$ & $29(27 \%)$ & $30(33 \%)$ & .006 \\
\hline Respiratory symptoms* & $243(50 \%)$ & $140(50 \%)$ & $59(52 \%)$ & $44(49 \%)$ & .99 \\
\hline $\begin{array}{l}\text { Dilated RV at diagnosis (at 2D } \\
\text { echo)* }\end{array}$ & $332(68 \%)$ & $186(66 \%)$ & $84(74 \%)$ & $62(69 \%)$ & .99 \\
\hline Cardiac catheterization* & $276(57 \%)$ & $154(55 \%)$ & $75(66 \%)$ & $47(52 \%)$ & .24 \\
\hline $\mathrm{Qp} / \mathrm{Qs} \uparrow$ & $2.1(1.5-2.6)$ & $2.1(1.4-2.7)$ & $1.8(1.5-2.3)$ & $2.1(1.6-2.2)$ & .99 \\
\hline $\mathrm{mPAP}, \mathrm{mm} \mathrm{Hg} \dagger$ & $24(18-34)$ & $26(20-40)$ & $20.5(17-30)$ & $24(18.5-28)$ & .006 \\
\hline Pulmonary hypertension* & $157(32 \%)$ & $112(40 \%)$ & $28(25 \%)$ & $17(19 \%)$ & .006 \\
\hline SAS to the right lung* & $248(51 \%)$ & $182(65 \%)$ & $49(43 \%)$ & $17(19 \%)$ & .006 \\
\hline Embolization of SAS* & $177(71 \%)$ & $132(47 \%)$ & $33(29 \%)$ & $12(13 \%)$ & .006 \\
\hline STPs* & $279(58 \%)$ & $142(51 \%)$ & $78(69 \%)$ & $59(66 \%)$ & .03 \\
\hline CMPs* & $206(42 \%)$ & $140(49 \%)$ & $35(31 \%)$ & $31(43 \%)$ & \\
\hline Time to last follow-up, $y^{\dagger}$ & $7.2(2.2-14.0)$ & $6.4(1.8-12.7)$ & $9.9(3.7-17.0)$ & $7.5(2.3-12)$ & .02 \\
\hline Overall mortality* & $41(8.7 \%)$ & $37(13 \%)$ & $4(3.5 \%)$ & - & .01 \\
\hline STPs hospital mortality* & $29(10 \%)$ & $25(17 \%)$ & $4(5 \%)$ & - & .08 \\
\hline STPs late mortality* & $11(3.9 \%)$ & $10(7 \%)$ & $1(1.3 \%)$ & - & .08 \\
\hline CMPs mortality* & $13(6.3 \%)$ & $13(9.3 \%)$ & - & - & .14 \\
\hline Symptoms at follow-up* & $172 / 451(37 \%)$ & $109(42 \%)$ & $33(31 \%)$ & $30(35 \%)$ & .24 \\
\hline
\end{tabular}

$C H D$, Congenital heart disease; $R V$, right ventricle; $2 D$, 2-dimensional; $Q p / Q s$, pulmonary-systemic flow ratio; $m P A P$, mean pulmonary artery pressure; $S A S$, systemic arterial supply; STPs, surgically treated patients; CMPs, clinically monitored patients. *Number of patients and percentage. †Median and interquartile range. Adapted with permission from Vida and colleagues. ${ }^{14}$

than $50 \%$ of them and, more rarely, computed tomography and magnetic resonance imaging (30\% of cases). Catheterization also allows the occlusion of aberrant systemic arterial supply by embolization coils, if required by hemodynamic conditions. From an electrocardiographic point of view, $50 \%$ of cases show right ventricular hypertrophy, in the form of a right bundle branch block. Pulmonary scintigraphy may be performed and usually shows that the left lung is hyperperfused compared with the right one ( $76 \%$ vs $24 \%)$.

\section{CLINICAL PRESENTATION AND MEDICAL TREATMENT}

The clinical presentation of SS varies and is closely related to the associated CHDs. In about $60 \%$ of cases, the diagnosis is made in children/neonates younger than 
TABLE 2. Demographics and surgical data of a series of patients with scimitar syndrome undergoing surgery $(n=279)$

\begin{tabular}{|c|c|}
\hline & Mean \pm SEM or $n$ \\
\hline \multicolumn{2}{|l|}{ Demographics } \\
\hline Male patients & $109 / 279(39 \%)$ \\
\hline Age at surgery, mo & $10.2 \pm 0.9$ \\
\hline \multicolumn{2}{|l|}{ Group of age at diagnosis } \\
\hline$<1 \mathrm{y}$ & $142 / 279(51 \%)$ \\
\hline$>1 \mathrm{y} ;<10 \mathrm{y}$ & $78 / 279(28 \%)$ \\
\hline$>10 \mathrm{y}$ & $59 / 279(21 \%)$ \\
\hline \multicolumn{2}{|l|}{ Characteristics } \\
\hline Symptoms at diagnosis & $210 / 279(76 \%)$ \\
\hline Cardiac symptoms at diagnosis & $147 / 279(53 \%)$ \\
\hline Respiratory symptoms at diagnosis & $142 / 279(51 \%)$ \\
\hline Need for medications at diagnosis & $48 / 279(17 \%)$ \\
\hline Pulmonary hypertension at diagnosis & $105 / 279(38 \%)$ \\
\hline $\mathrm{mPAP}$ at diagnosis, $\mathrm{mm} \mathrm{Hg}$ & $29.2 \pm 0.1$ \\
\hline Associated CHDs & $194 / 279(69 \%)$ \\
\hline Atrial septal defect & $168 / 279(60 \%)$ \\
\hline Complex CHDs & $63 / 279(23 \%)$ \\
\hline SAS to the right lung & $130 / 279(47 \%)$ \\
\hline Coil embolization of SAS & $93 / 279(33 \%)$ \\
\hline \multicolumn{2}{|l|}{ Degree of right pulmonary hypoplasia } \\
\hline Mild & $110 / 279(39 \%)$ \\
\hline Moderate & $61 / 279(22 \%)$ \\
\hline Severe & $18 / 279(6 \%)$ \\
\hline \multicolumn{2}{|l|}{ Operative data } \\
\hline \multicolumn{2}{|l|}{ Type of procedure } \\
\hline Corrective surgery & $254 / 279(91 \%)$ \\
\hline Resective & $25 / 279(9 \%)$ \\
\hline \multicolumn{2}{|l|}{ Type of corrective surgery } \\
\hline Intracardiac baffle & $176 / 254(69 \%)$ \\
\hline Direct scimitar vein reimplantation & $78 / 254(31 \%)$ \\
\hline \multicolumn{2}{|l|}{ Type of resective surgery } \\
\hline Lobectomy & $18 / 25(72 \%)$ \\
\hline Pneumectomy & $7 / 25(28 \%)$ \\
\hline Associated surgical procedure & $101 / 279(36 \%)$ \\
\hline CBP time, min & $127.2 \pm 5.4$ \\
\hline Aortic crossclamp time, $\min$ & $62.5 \pm 3.2$ \\
\hline Circulatory arrest time, min & $28.3 \pm 6.4$ \\
\hline
\end{tabular}

SEM, Standard error of the mean; $M P A P$, mean pulmonary artery pressure; $C H D$, congenital heart disease; $S A S$, systemic arterial supply; $C B P$, cardiopulmonary bypass.

the first year of age. This form, previously known as "infantile form" is more frequently characterized by symptoms at diagnosis, such as congestive heart failure $(60 \%$ of patients), failure to thrive, and tachypnea. ${ }^{14}$ In addition, $50 \%$ of these patients have respiratory symptoms, such as difficulty breathing, recurrent upper respiratory tract infections, cyanosis, and pneumonia. This group is also frequently affected by the presence of collateral arteries that supply the right lung and by associated CHDs. For this reason, these patients are more likely to be diagnosed early in life and treated surgically.

In contrast, an "adult form" has been identified as a milder manifestation of the syndrome. ${ }^{8}$ In our case series, we have divided this spectrum into 3 different subcategories based on age: neonates within 1 year, children from 1 to 10 years, and adolescents/adults older than 10 years. Fewer children were asymptomatic at diagnosis (65\% of cases), with a very low percentage of cardiac symptoms $(27 \%$ of cases) and pulmonary hypertension (25\% of cases) (Table 1 ). Interestingly, we have confirmed that in more than $50 \%$ of adolescents/adults, SS appears as an isolated form, with a slight degree of right pulmonary hypoplasia, absence of symptoms in $33 \%$ of patients, or history of recurrent upper respiratory tract infections in $50 \%$ of them. ${ }^{14}$

Medical treatment in patients who are not directed at surgery (ie, clinically monitored patients [CMPs]) depends on the presence and type of symptoms at diagnosis. Cardiac symptoms are generally managed with diuretics and $\mathrm{Na}^{+} /$ $\mathrm{K}^{+}$ATPase inhibitors, whereas respiratory symptoms may require drugs such as beta-agonist and ipratropium bromide, antibiotics, and cortisonics. As mentioned previously, patients may present with an abnormal systemic supply to the right lung that can be treated with coil embolization, to reduce the $\mathrm{Qp} / \mathrm{Qs}$ ratio.

\section{SURGICAL MANAGEMENT}

More than one half of patients $(57 \%)$ are treated surgically (ie, surgically treated patients [STPs]), with an average age of about 10 years at surgery. Neonates patients are diagnosed earlier ( $51 \%$ of cases), particularly in the presence of cardiac symptoms and associated CHDs ${ }^{14}$ (Tables 1 and 2). Pulmonary hypertension (defined as a the presence of a mean pulmonary artery pressure $>25 \mathrm{~mm} \mathrm{Hg}$ at rest or $50 \%$ above systemic level) is often present before surgery (38\% of patients) and must always be addressed before surgery, either by medical treatment or by reducing the $\mathrm{Qp} / \mathrm{Qs}$ ratio by coil embolization. Therefore, isolated forms of SS are generally treated in the case of a $\mathrm{Qp} / \mathrm{Qs}$ ratio $>1.5: 1$ or $\mathrm{Qp} / \mathrm{Q}$ s ratio $<1.5: 1$ with a clinically treated pulmonary hypertension. However, the right choice for this particular group of patients remains controversial.

Surgical treatment includes correction of abnormal venous drainage in most patients $(>90 \%)$, but right lung resection may be required in more severe forms. In any case, nonetheless, the abnormal systemic supply to the right lung should be ligated and all associated CHDs should be repaired.

Surgical options for the redirection of the anomalous $\mathrm{SV}$ in the left atrium can consist of intracardiac baffle (69\% of cases) or direct SV reimplantation $(31 \%$ of cases). ${ }^{14}$ There are several surgical corrective options for the pulmonary venous return re-routing, ${ }^{16}$ which can be accomplished both via a right thoracotomy or sternotomy (Figure 1, Video 1). One of the first options described involved the creation of a pericardial tunnel 


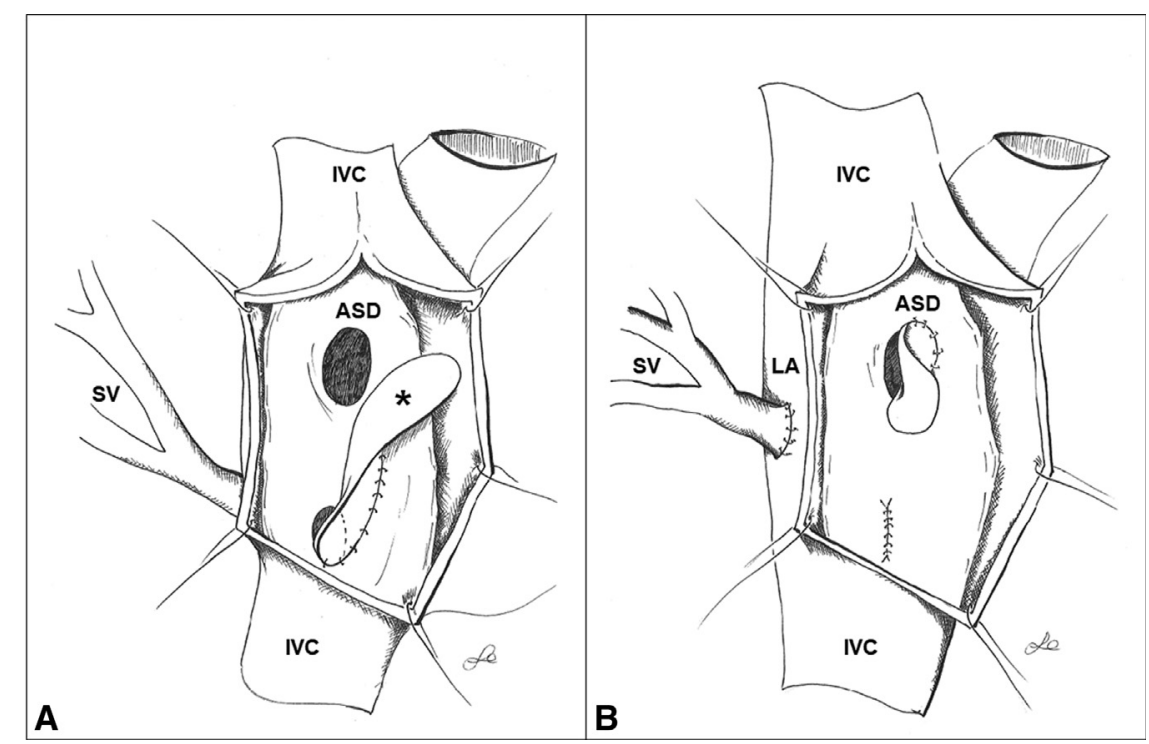

FIGURE 1. A, Intracardiac baffle technique. B, Reimplantation technique. The asterisk shows the intracardiac baffle. SV, Scimitar vein; $A S D$, atrial septal defect; $I V C$, inferior vena cava; $L A$, left atrium.

baffling flow from the orifice of the SV at the level of the IVC through the right atrium and then the connection of the baffle to the sides of the atrial septal defect ${ }^{17}$ (Figure 1, A). Another technique includes the resection of the SV orifice with a cuff of the IVC and subsequent reimplantation in the left atrium and IVC patch enlargement $^{18}$ (Figure 1, B). Brown and colleagues ${ }^{19}$ described a direct anastomosis of the SV, with full dissection of the $\mathrm{SV}$, incision of the diaphragm, and reimplantation through a window excised posterior to the phrenic nerve. Recently, new techniques have been proposed, such that by Lugones and García, $^{20}$ in which the pulmonary venous return is widely connected to the left atrium through a tunnel constructed with the in situ pericardium.

Nowadays, the role of a right pulmonary lobectomy or more rarely a right pulmonary pneumectomy has been limited to the presence of severe right pulmonary hypoplasia, recurrent upper respiratory tract infections unresponsive to medical treatment, diffuse bronchiectasia, persistent hemoptysis, or intra-atrial baffles thrombosis after corrective surgery.

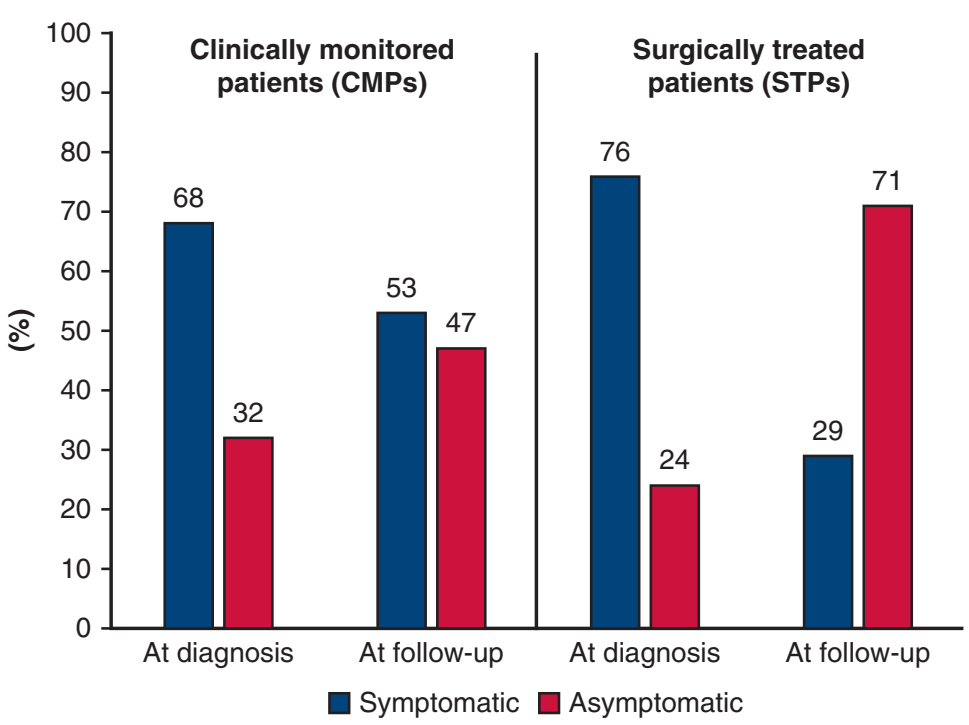

FIGURE 2. Bar plots showing the difference in the presence of symptoms at the time of diagnosis and at the time of follow-up between clinically monitored patients $(C M P s)$ and surgically treated patients $(S T P s)$. The associations among clinical variables and outcome measures are based on a logistic regression model for binary outcomes (odds ratio, 0.16 ; confidence interval, 0.08-0.32). 
TABLE 3. Outcomes of a series of scimitar syndrome patients undergoing surgery $(n=279)$

\begin{tabular}{|c|c|}
\hline & Mean \pm SEM or $n$ \\
\hline \multicolumn{2}{|l|}{ Early outcomes } \\
\hline Postoperative complications & $93 / 279(33 \%)$ \\
\hline Respiratory failure & $36 / 93(39 \%)$ \\
\hline Congestive heart failure & $21 / 93(26 \%)$ \\
\hline Sepsis & $16 / 93(17 \%)$ \\
\hline Pericardial/pleural effusion & $14 / 93(15 \%)$ \\
\hline Arrhythmia & $14 / 93(15 \%)$ \\
\hline Pulmonary hypertensive crisis & $14 / 93(15 \%)$ \\
\hline Bleeding & $8 / 93(9 \%)$ \\
\hline Delayed chest closure & $6 / 93(6 \%)$ \\
\hline Hospital mortality & $17 / 279(6 \%)$ \\
\hline $\begin{array}{l}\text { Hospital mortality in case of } \\
\text { corrective surgery }\end{array}$ & $8 / 254(3 \%)$ \\
\hline $\begin{array}{l}\text { Hospital mortality in case of } \\
\text { resective surgery }\end{array}$ & $9 / 25(36 \%)$ \\
\hline \multicolumn{2}{|l|}{ Late outcomes } \\
\hline Late mortality & $11 / 279(4 \%)$ \\
\hline Overall mortality & $28 / 279(10 \%)$ \\
\hline Congestive heart failure & $16 / 28(57 \%)$ \\
\hline Pulmonary hypertension & $6 / 28(22 \%)$ \\
\hline Respiratory failure & $4 / 28(14 \%)$ \\
\hline Bleeding & $2 / 28(7 \%)$ \\
\hline Symptoms at follow-up & $80 / 279(29 \%)$ \\
\hline Cardiac symptoms at follow-up & $49 / 279(18 \%)$ \\
\hline Respiratory symptoms at follow-up & $31 / 279(11 \%)$ \\
\hline Need for medications at follow-up & $52 / 279(19 \%)$ \\
\hline \multicolumn{2}{|l|}{ Scimitar vein anastomosis presenting } \\
\hline Stenosis & $57 / 254(22 \%)$ \\
\hline Occlusion & $6 / 254(2 \%)$ \\
\hline $\begin{array}{l}\text { Reoperation/recatheterization in case of } \\
\text { corrective surgery }\end{array}$ & $42 / 254(17 \%)$ \\
\hline Freedom from above, y & $6.3 \pm 0.4$ \\
\hline
\end{tabular}

$S E M$, Standard error of the mean.

Postoperative complications occur in $33 \%$ of the patients and usually include respiratory failure $(39 \%)$ and congestive heart failure $(26 \%)$. The hospital mortality rate is generally low $(6 \%)$ and lower for patients undergoing corrective surgery $(3 \%)$, rather than resective procedures $(36 \%)$. Late mortality is around $4 \%$ at a mean follow-up of 7 years, with an overall mortality of $10 \%$ of the patients.

\section{LATE SURGICAL OUTCOMES VERSUS NATURAL HISTORY}

Overall survival probability at 30 years of age is $88 \%$ and is lower in patients with associated CHDs and pulmonary hypertension. In the STPs, most of the deaths are caused by congestive heart failure $(57 \%)$, but also by pulmonary hypertension $(22 \%)$ and respiratory failure $(14 \%)$.

Most STPs are asymptomatic at the last clinical examination (71\%) (Figure 2) and only $20 \%$ of patients still need medications (Table 3 ). In contrast, there is a slight increase in symptomatic patients in clinically monitored patients due

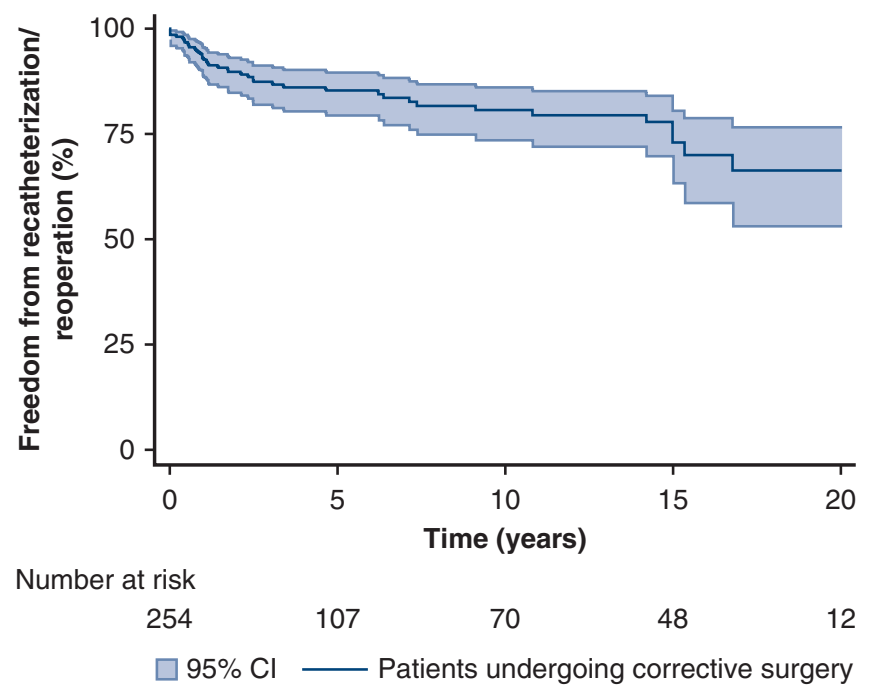

FIGURE 3. Kaplan-Meier curves showing the freedom from interventional cardiac catheterization or reoperation on "scimitar vein" anastomosis after corrective surgery $(\mathrm{n}=254$ patients). $95 \% \quad C I, 95 \%$ confidence interval.

to both for cardiac and respiratory symptoms. None of the asymptomatic patients at diagnosis develops symptoms after surgical treatment. ${ }^{14}$

Nevertheless, almost one quarter of the STPs present SV drainage disfunction after a corrective procedure. This included stenosis in $22 \%$ of cases or rarely total occlusion in $2 \%$ of patients. This diagnosis is not related to the type of corrective technique ${ }^{14}$ used and is more frequent in neonates/infants $(33 \%)$ than in either children $(20 \%)$ or adolescents/adults $(14 \%)$. In addition, we found that there is an inverse linear correlation between age at correction and stenosis/occlusion of the scimitar drainage (the younger the patient, the higher the incidence of stenosis/occlusion). ${ }^{14}$ For this reason, an intracardiac baffle is usually recommended in younger patients whereas direct reimplantation is recommended in older ones. Of these patients with SV occlusion, $17 \%$ need an interventional cardiac catheterization or reoperation to address the failure, with average freedom of more than 6 years from the time of the first surgery (Figure 3, Table 3). In some patients with obstruction of the SV baffle, a pneumonectomy is required, and hemoptysis is often the first indication of this complication.

\section{CONCLUSIONS}

The clinical presentation of patients with SS varies, mainly depending on age at diagnosis and associated CHDs. Pulmonary hypertension and the presence of associated CHDs are negative prognostic factors in patient survival, regardless of patient history.

Surgical treatment usually involves redirection of the anomalous pulmonary venous drainage into the left atrium. This usually provides excellent results with regards to symptom relief and is superior in reducing the risk of 


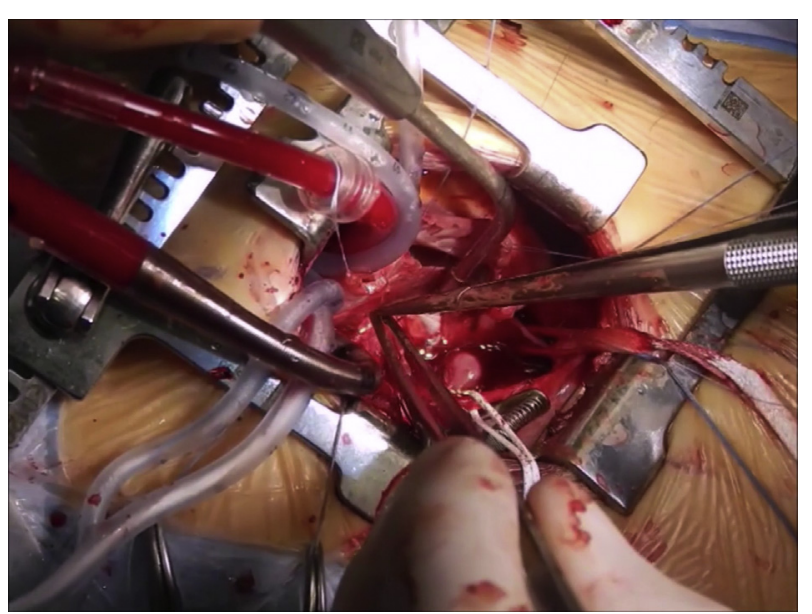

VIDEO 1. Video showing the surgical correction of a patient with scimitar syndrome by direct reimplantation in the left atrium via a right thoracotomy. Video available at: https://www.jtcvs.org/article/S2666-2507(20) 30044-4/fulltext.

developing late symptoms with respect to clinically monitored or medically treated patients.

However, almost $25 \%$ of the STPs undergoing corrective surgery present $\mathrm{SV}$ drainage disfunction, with stenosis or occlusion at the level of the SV anastomosis. This happens more frequently in young children and requires interventional cardiac catheterization or reoperation to treat related morbidities.

Treatment decisions are still challenging, especially in patients with less-severe forms who are often asymptomatic. New data obtained from large multicenter studies have shown that surgical treatment should be considered in isolated forms only when the scimitar drainage causes significant pulmonary overload. Correction of associated CHDs and occlusion of systemic arterial supply may be useful, thus postponing a full correction to an older age. Confirmatory prospective randomized clinical trials are necessary to reach more definitive conclusions.

\section{Conflict of Interest Statement}

Authors have nothing to disclose with regard to commercial support.

\section{References}

1. Vida VL. The Complete Reference for Scimitar Syndrome. London: Academic Press; 2017.

2. Opotowsky AR, Webb GD. A battle in the crusade to understand scimitar syndrome. Eur Heart J. 2018;39:1012-4.

3. Halasz NA, Halloran KH, Liebow AA. Bronchial and arterial anomalies with drainage of the right lung into the inferior vena cava. Circulation. 1956;14: 826-46.

4. Neill CA, Ferencz C, Sabiston D, Sheldon H. The familial occurrence of hypoplastic right lung with systemic arterial supply and venous drainage "scimitar syndrome." Bull Johns Hopkins Hosp. 1960;107:1-21.

5. Wang CC, Wu ET, Chen SJ, Lu F, Huang SC, Wang JK, et al. Scimitar syndrome: incidence, treatment, and prognosis. Eur J Pediatr. 2008;167:155-60.

6. Vida VL, Speggiorin S, Padalino MA, Crupi G, Marcelletti C, Zannini L, et al. The scimitar syndrome: an Italian multicenter study. Ann Thorac Surg. 2009; 88:440-4

7. Vida VL, Padalino MA, Boccuzzo G, Tarja E, Berggren H, Carrel T, et al. Scimitar syndrome: a European Congenital Heart Surgeons Association (ECHSA) multicentric study. Circulation. 2010;122:1159-66.

8. Dupuis C, Charaf LAC, Brevière GM, Abou P, Rémy-Jardin M, Helmius G. The "adult" form of the scimitar syndrome. Am J Cardiol. 1992;70:502-7.

9. Dupuis C, Charaf LAC, Breviere GM, Abou P. "Infantile" form of the scimitar syndrome with pulmonary hypertension. Am J Cardiol. 1993;71:1326-30.

10. Dusenbery SM, Geva T, Seale A, Valente AM, Zhou J, Sena L, et al. Outcome predictors and implications for management of scimitar syndrome. Am Heart J. 2013;165:770-7.

11. Vida VL, Padrini M, Boccuzzo G, Agnoletti G, Bondanza S, Butera G, et al. Natural history and clinical outcome of "uncorrected" scimitar syndrome patients: a multicenter study of the Italian Society of Pediatric Cardiology. Rev Española Cardiol (Engl Ed). 2013;66:556-60.

12. Brink J, Yong MS, d'Udekem Y, Weintraub RG, Brizard CP, Konstantinov IE. Surgery for scimitar syndrome: the Melbourne experience. Interact Cardiovasc Thorac Surg. 2015;20:31-4.

13. Wang H, Kalfa D, Rosenbaum MS, Ginns JN, Lewis MJ, Glickstein JS, et al. Scimitar syndrome in children and adults: natural history, outcomes, and risk analysis. Ann Thorac Surg. 2018;105:592-8.

14. Vida VL, Guariento A, Milanesi O, Gregori D, Stellin G; Scimitar Syndrome Study Group. The natural history and surgical outcome of patients with scimitar syndrome: a multi-centre European study. Eur Heart J. 2018;39: 1002-11.

15. Gudjonsson U, Brown JW. Scimitar syndrome. Semin Thorac Cardiovasc Surg Pediatr Card Surg Annu. 2006;9:56-62.

16. Çiçek S, Arslan AH, Ugurlucan M, Yildiz Y, Ay S. Scimitar syndrome: the curved Turkish sabre. Semin Thorac Cardiovasc Surg Pediatr Card Surg Annu. 2014;17: 56-61.

17. Zubiate P, Kay JH. Surgical correction of anomalous pulmonary venous connection. Ann Surg. 1962;156:234-50.

18. Varghese R, Omoregbee B, Saheed S. Scimitar syndrome: surgical approach to an unusual anatomy of the scimitar vein. Ann Pediatr Cardiol. 2016;9: $173-5$.

19. Brown JW, Ruzmetov M, Minnich DJ, Vijay P, Edwards CA, Uhlig PN, et al. Surgical management of scimitar syndrome: an alternative approach. J Thorac Cardiovasc Surg. 2003;125:238-45.

20. Lugones I, García R. A new surgical approach to scimitar syndrome. Ann Thorac Surg. 2014;97:353-5. 